\title{
A Tutorial on Electrochemical Impedance Spectroscopy
}

\author{
Mark E. Orazem* • Bernard Tribollet
}

Received: date / Accepted: date

\begin{abstract}
Electrochemical impedance spectroscopy is presented as a transfer-function technique that is applied to electrochemical systems. Examples are provided that show the unique capability of the technique to provide valuable information that may otherwise be difficult or impossible to obtain.
\end{abstract}

Keywords Transfer Functions · Corrosion · Fuel Cells · Oxide Films

Impedance spectroscopy is an electrochemical technique with broad applications that is used in fields such as corrosion, biomedical devices, semiconductors and solid-state devices, sensors, batteries, fuel cells, electrochemical capacitors, dielectric measurements, coatings, electrochromic materials, analytical chemistry, electrocatalysis, and imaging. The objective of this tutorial is to provide a brief and somewhat qualitative introduction to the subject of electrochemical impedance spectroscopy. This material, presented at the "First Workshop of Material Science for Corrosion Protection" in Santiago, Chile, November, 2017, is an extension of an introductory chapter presented in Orazem and Tribollet[1].

paper published as M. E. Orazem and B. Tribollet, "A Tutorial on Electrochemical Impedance Spectroscopy," invited paper, Chem Texts, 6, 12 (2020).

*Corresponding author. Mark E. Orazem

Department of Chemical Engineering, University of Florida, Gainesville, FL, 32611, USA

Tel.: +1-352-392-6207

Fax: +1-352-392-9513

E-mail: meo@che.ufl.edu

Bernard Tribollet

Sorbonne Université, CNRS, Laboratoire Interfaces et Systémes Electrochimiques, LISE, F-75005, Paris, France

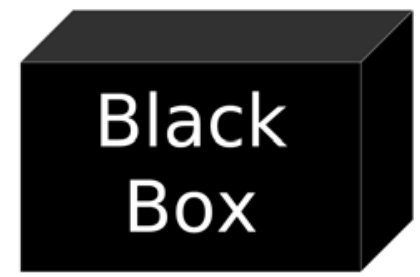

Fig. 1 Representation of a black box. Taken from Orazem and Tribollet.[1]

Consider the system with unknown properties that is shown in Figure 1 and labeled "black box". The objective of the exercise is to learn the properties of the box in an effort to understand what it is. A series of measurements may be considered to interrogate the black box by imposing an input and measuring the resulting output. For example, imagine that the box is placed in a dark room and is then subject to light of a specified wavelength. If a response is seen, such as an electrical current, the contents of the box may be considered to be photoactive. To explore the kinetics associated with the discharge of current from absorbed photons, the light intensity could be modulated. An alternative approach could be to impose an electrical potential and to observe the resulting current. Modulation of the input signal would allow exploration of the influence of storage of charge within the box and the kinetics of processes that transform the potential to current.

The relationship between input and output is called a "transfer function". Impedance spectroscopy is a special case of a transfer function. 


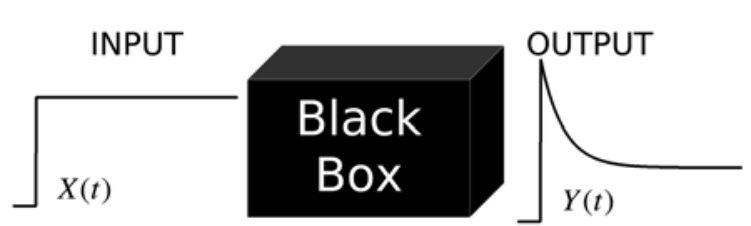

(a)

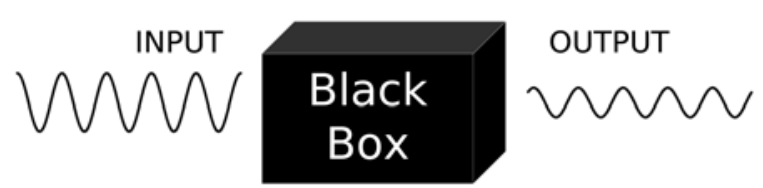

(b)

Fig. 2 Representation of the system response $Y(t)$ to $X(t)$ defined as: a) step change input; and b) sinusoidal input with frequency $\omega$. Taken from Orazem and Tribollet.[1]

\section{Transfer Function}

The transfer function provides a compact description of the input-output relation for a linear time-invariant (LTI) system. Due to the fact that most signals can be decomposed into summation of sinusoids via Fourier series, the response of a system is characterized by the frequency response of the system. A generalized system is illustrated in Figure 2(a). The response to a step input signal $X(t)$ shows different long and short time behaviors that can be represented as the dependence of the transfer function on frequency.

The short-time behavior corresponds to high frequencies, and the long-time behavior corresponds to low frequencies. For an electrochemical system, charging of the electrode-electrolyte interface occurs rapidly and is associated with the high-frequency or short-time response. Diffusion is a slower process with a large time constant and correspondingly a smaller characteristic frequency.

The appropriate frequency range for the measurement is determined in accordance to the system under study. For example, the phenomena associated with a typical electrochemical system include double-layer charging, faradaic reactions, and diffusion.

Consider, for example, a disk electrode with radius $r_{0}=0.25 \mathrm{~cm}$ and a capacity $C_{0}=20 \mu \mathrm{F} / \mathrm{cm}^{2}$. The disk is immersed in an electrolyte of resistivity $\rho=10 \Omega \mathrm{cm}$. Assume that the faradaic reaction has an exchange current density $i_{0}=1 \mathrm{~mA} / \mathrm{cm}^{2}$ and that the disk is rotating at $\Omega=400 \mathrm{rpm}$. The kinematic viscosity of the electrolyte is $\nu=10^{-2} \mathrm{~cm}^{2} / \mathrm{s}$.

The time constant for charging the electrode surface is given by

$\tau_{\mathrm{C}}=C_{0} R_{\mathrm{e}}$ where $R_{\mathrm{e}}$ is the ohmic resistance, given for a disk electrode in units of $\Omega$ as[2]

$R_{\mathrm{e}}=\frac{1}{4 \kappa r_{0}}=\frac{\rho}{4 r_{0}}$

or, in units of $\Omega \mathrm{cm}^{2}$, as

$R_{\mathrm{e}}=\frac{\pi r_{0} \rho}{4}$

For the parameters given, the time constant is $\tau_{\mathrm{C}}=$ $0.04 \mathrm{~ms}$. The corresponding characteristic angular frequency is given by

$\omega_{\mathrm{C}}=\frac{1}{\tau_{\mathrm{C}}}$

and, in units of $\mathrm{Hz}$,

$f_{\mathrm{C}}=\frac{1}{2 \pi \tau_{\mathrm{C}}}$

Thus, for a time constant $\tau_{\mathrm{C}}=0.04 \mathrm{~ms}$, the characteristic frequency is $4.1 \mathrm{kHz}$.

The time constant for a faradaic reaction is given by

$\tau_{\mathrm{t}}=C_{0} R_{\mathrm{t}}$

where $R_{\mathrm{t}}$ is the charge-transfer resistance, given, for linear kinetics on a disk electrode, by

$R_{\mathrm{t}}=\frac{\mathrm{R} T}{n \mathrm{~F} i_{0}}$

Equations (6) and (7) yield a time constant of $0.51 \mathrm{~ms}$ and a characteristic frequency of $310 \mathrm{~Hz}$.

The time constant for diffusion to a rotating disk electrode is given by

$\tau_{\mathrm{D}}=\frac{\delta_{\mathrm{N}}^{2}}{D_{\mathrm{i}}}$

where $D_{\mathrm{i}}$ is the diffusion coefficient for the reacting species and $\delta_{\mathrm{N}}$ is the diffusion layer thickness given as a function of rotation speed by

$\delta_{\mathrm{N}, \mathrm{i}}=\Gamma(4 / 3)\left(\frac{3}{\mathrm{a}}\right)^{1 / 3} \frac{1}{\mathrm{Sc}_{\mathrm{i}}^{1 / 3}} \sqrt{\frac{\nu}{\Omega}}=1.61 \frac{1}{\mathrm{Sc}_{\mathrm{i}}^{1 / 3}} \sqrt{\frac{\nu}{\Omega}}$

where $\mathrm{Sc}_{\mathrm{i}}=\nu / D_{\mathrm{i}}$ is the Schmidt number which has a value $\mathrm{Sc}_{\mathrm{i}}=1000$ for $\nu=10^{-2} \mathrm{~cm}^{2} / \mathrm{s}$ and a typical diffusivity $D_{\mathrm{i}}=10^{-5} \mathrm{~cm}^{2} / \mathrm{s}$. The time constant for diffusion of a species with a diffusivity of $10^{-5} \mathrm{~cm}^{2} / \mathrm{s}$ is equal to $0.41 \mathrm{~s}$. The corresponding characteristic frequency is $0.4 \mathrm{~Hz}$.

Thus, the frequency range for an impedance measurement for disk electrode can be from $10 \mathrm{kHz}$ to 


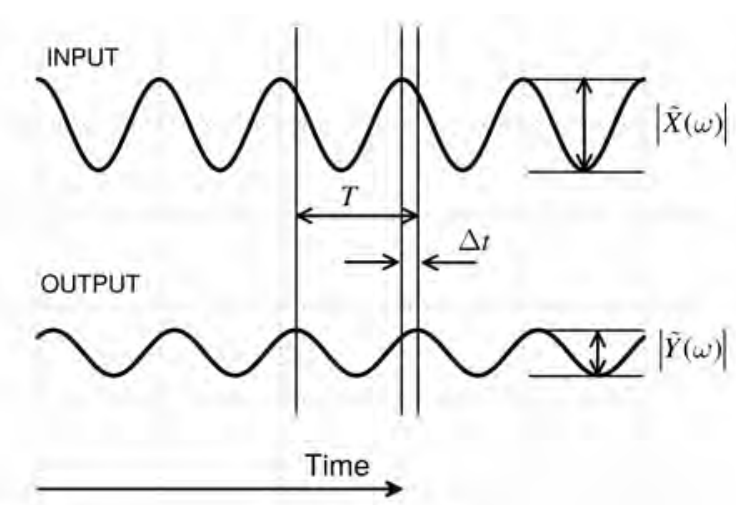

Fig. 3 Schematic representation of the calculation of the transfer function for a sinusoidal input at frequency $\omega$. The time lag between the two signals is $\Delta t$ and the period of the signals is $T$. Taken from Orazem and Tribollet.[1]

$10 \mathrm{mHz}$. The frequency range may be limited by instrument and wiring limitations that constrain the highfrequency limit and by nonstationary processes that constrain the low-frequency limit.

Experiments are conducted in the time domain. If the input signal is sinusoidal, as shown in Figure 2(b),

$X(t)=\bar{X}+|\Delta X| \cos (\omega t)$

where $\bar{X}$ is the steady-state or time-invariant part of the signal, and $|\Delta X|$ represents the magnitude of the oscillating part of the signal. When $|\Delta X|$ is sufficiently small that the response is linear, the output will have the form of the input and be at the same frequency, i.e.,

$Y(t)=\bar{Y}+|\Delta Y| \cos (\omega t+\varphi)$

where $\varphi$ is the phase lag between the input and output signals. An alternative representation of the timedomain expressions is

$X(t)=\bar{X}+\operatorname{Re}\{\tilde{X} \exp (\mathrm{j} \omega t)\}$

and

$Y(t)=\bar{Y}+\operatorname{Re}\{\tilde{Y} \exp (\mathrm{j} \omega t)\}$

respectively, where $\tilde{X}$ and $\tilde{Y}$ are complex quantities called phasors that are functions of frequency but are independent of time. The transfer function is a function of frequency and is independent of both time and the magnitude of the input signal. While the measurements are made in time domain, the determination of the transfer function is obtained from subsequent analysis.

The calculation of the transfer function at a given frequency $\omega$ is presented schematically in Figure 3. The ratio of the amplitudes of the output and input signals yields the magnitude of the transfer function. The phase angle in units of radians can be obtained as

$\varphi(\omega)=2 \pi \frac{\Delta t}{T}$

If $\Delta t=0$, the phase angle is equal to zero. Similarly, the phase angle is equal to zero if $\Delta t=T$ as the phase angle in equation (14) is a full period $2 \pi$. As shown in Figure 3, the output lags the input, and the phase angle has a positive value.

The transfer function is, therefore, characterized by two parameters: the gain

$|H(\omega)|=\frac{|Y|}{|X|}=\frac{|\tilde{Y}(\omega)|}{|\widetilde{X}(\omega)|}$

and the phase shift $\varphi(\omega)$. These two parameters can be written in the form of a complex number with a magnitude $|H(\omega)|$ and a phase $\varphi(\omega)$ or with a real part expressed as $|H(\omega)| \cos (\varphi(\omega))$ and an imaginary part $|H(\omega)| \sin (\varphi(\omega))$.

Generally the input signal is considered to be a reference for the phase. In this case, the corresponding complex number for the input is real, i.e., $\widetilde{X}(\omega)$ and the output signal is a complex number $\tilde{Y}(\omega)$ with a magnitude $|\tilde{Y}(\omega)|$ and a phase $\varphi(\omega)$. Thus,

$H(\omega)=\frac{\tilde{Y}(\omega)}{\widetilde{X}(\omega)}=\frac{|\widetilde{Y}(\omega)|}{|\widetilde{X}(\omega)|}(\cos \varphi(\omega)+\mathrm{j} \sin \varphi(\omega))$

For an electrical or an electrochemical system, the input is usually a potential, the output is a current, and the transfer function is called admittance. In the particular case where the input is a current and the output is a potential, the transfer function is an impedance. The transfer function is, however, a property of the system that is independent of the input signal. As the admittance is the inverse of the impedance,

$Z(\omega)=\frac{\widetilde{V}(\omega)}{\widetilde{i}(\omega)}$

Generally only the impedance is considered even if the measurement corresponds to an admittance. The measured impedance can have a strong dependence on the applied frequency. By analyzing the impedance as a function of frequency, a transfer-function model could be defined which takes into account all time constants of the corresponding system.

Impedance spectroscopy is much more than a simple application of Ohm's law, i.e., $V=I R$. The expression $V=I R$ represents a steady-state measurement. For a system consisting of a resistor, shown in Figure 


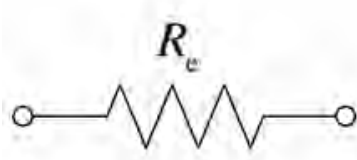

(a)

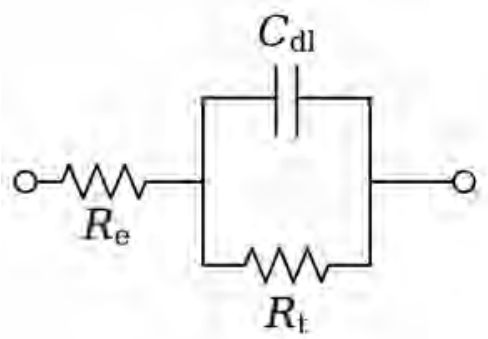

(b)

Fig. 4 Electrical systems: a) a resistor and b) a resistor in series with the parallel combination of a capacitor and a resistor. Taken from Orazem and Tribollet.[1]

4(a), the measurement of current at an applied potential yields the value of the resistor, i.e., $\bar{V} / \bar{I}=R_{\mathrm{e}}$. For potentiostatic impedance measurements, application of an oscillatory potential

$V=\bar{V}+|\Delta V| \cos (\omega t)$

yields a current

$I=\bar{I}+|\Delta I| \cos (\omega t+\varphi)$

where $\varphi$ is the phase lag between the current and potential. Equation (18) is mathematically equivalent to

$V=\bar{V}+\operatorname{Re}\{\tilde{V} \exp (\mathrm{j} \omega t)\}$

and equation (19) is mathematically equivalent to

$I=\bar{I}+\operatorname{Re}\{\widetilde{I} \exp (\mathrm{j} \omega t)\}$

The impedance for the resistor shown in Figure 4(a), expressed as

$Z=\frac{\widetilde{V}}{\widetilde{I}}=R_{\mathrm{e}}$

yields the same information that could be obtained from the steady-state measurement $\bar{V} / \bar{I}=R_{\mathrm{e}}$.

The circuit presented in Figure 4(b) may be considered to represent a simple potential-dependent electrochemical reaction. The steady-state measurement of current at an applied potential yields

$\frac{\bar{V}}{\bar{I}}=R_{\mathrm{e}}+R_{\mathrm{t}}$ from which the contributions of $R_{\mathrm{e}}$ and $R_{\mathrm{t}}$ cannot be distinguished and the contribution of the parallel capacitance cannot be discerned. In contrast, the impedance response may be expressed as

$Z=\frac{\widetilde{V}}{\widetilde{I}}=R_{\mathrm{e}}+\frac{R_{\mathrm{t}}}{1+\mathrm{j} \omega R_{\mathrm{t}} C_{\mathrm{dl}}}$

from which the parameters $R_{\mathrm{e}}, R_{\mathrm{t}}$, and $C_{\mathrm{dl}}$ may be obtained easily by using graphical methods.[1,3]

\section{Applications of Impedance Spectroscopy}

Impedance spectroscopy has been applied to many electrochemical systems. The examples given below are intended to demonstrate the power of impedance spectroscopy. The discussion of the influence of adsorbed intermediates on impedance response suggests that some properties can be studied only by measurement of the electrochemical impedance. Impedance spectroscopy can be used to measure rates of corrosion that are too small to be assessed by weight loss measurements. Impedance spectroscopy also can provide an inexpensive way to determine the thickness of oxide layers. The analyses presented in this section are qualitative. The reader is directed to the cited literature for more detailed mathematical treatments.

\subsection{Presence of Adsorbed Intermediates}

Some properties can be studied only by measurement of the electrochemical impedance. For example, impedance may be used to demonstrate the existence of an adsorbed reaction intermediate in the form of a fraction of monolayer in the case of iron dissolution in sulphuric acid. A current-potential curve obtained on a stationary iron electrode in $0.5 \mathrm{M}$ sulfuric acid solution is presented in Figure 5(a).[4] The scan rate was $2 \mathrm{mV} / \mathrm{sec}$. The potential was applied to the iron electrode from the open-circuit potential, activating the iron electrode, to a higher potential, passivating the electrode surface. The potential $E=-0.925 \mathrm{~V}$ (SSE) in Figure 5(b) represents a steady-state condition for which impedance measurements were performed.

Bockris and coworkers[5] proposed a reaction model in which two consecutive steps are coupled by an adsorbed intermediate. The anodic dissolution of iron can be described in simplified form as

$\mathrm{Fe} \stackrel{K_{1}}{\longrightarrow} \mathrm{Fe}_{\mathrm{ads}}^{+}+\mathrm{e}^{-}$

and

$\mathrm{Fe}_{\text {ads }}^{+} \stackrel{K_{2}}{\longrightarrow} \mathrm{Fe}^{2+}+\mathrm{e}^{-}$ 


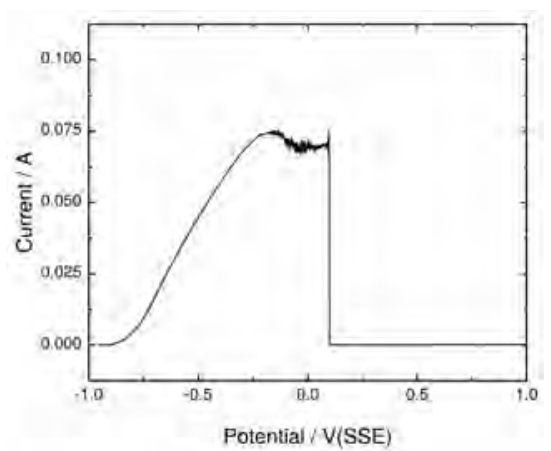

(a)

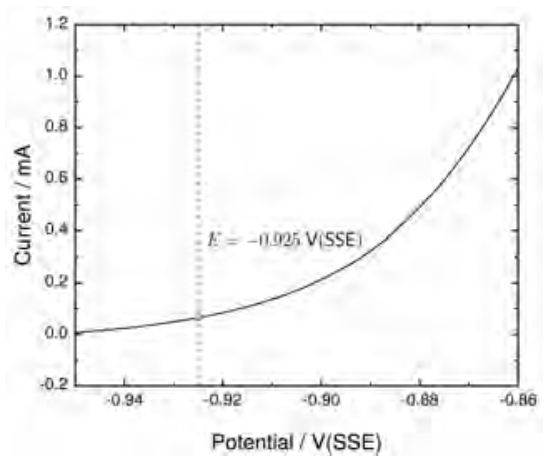

(b)

Fig. 5 The polarization curve for a stationary iron electrode in $0.5 \mathrm{M} \mathrm{H}_{2} \mathrm{SO}_{4}$ : a) a scan including both the active and passivated regions; b) zoomed portion of part (a) showing the potential at which the impedance measurement was performed. Data taken from Wu et al.[4].

The iron first oxidizes and forms a monovalent intermediate adsorbed on the electrode surface. This reaction is followed by the oxidation of the intermediate. The ferrous ion is soluble and diffuses away from the electrode. Epelboin and Keddam[6], Armstrong et al.[7], and Epelboin et al.[8] showed that the inductive loops observed in the low-frequency impedance response could be attributed to partial coverage of the iron surface by an adsorbed intermediate. Such a film is too thin to be observed directly.

The faradaic impedance for this system can be expressed as

$$
Z_{\mathrm{F}}=\frac{1}{\frac{1}{R_{\mathrm{t}, \mathrm{eff}}}+\frac{A}{B+\mathrm{j} \omega}}
$$

where $R_{\mathrm{t}, \text { eff }}$ represents the effective charge-transfer resistance for reactions (25) and (26). The inductive term is scaled by a constant $A$ that can be expressed in terms of the dependence of the steady-state faradaic current on the fractional coverage of the surface and the dependence of the time-rate-of-change of fractional coverage

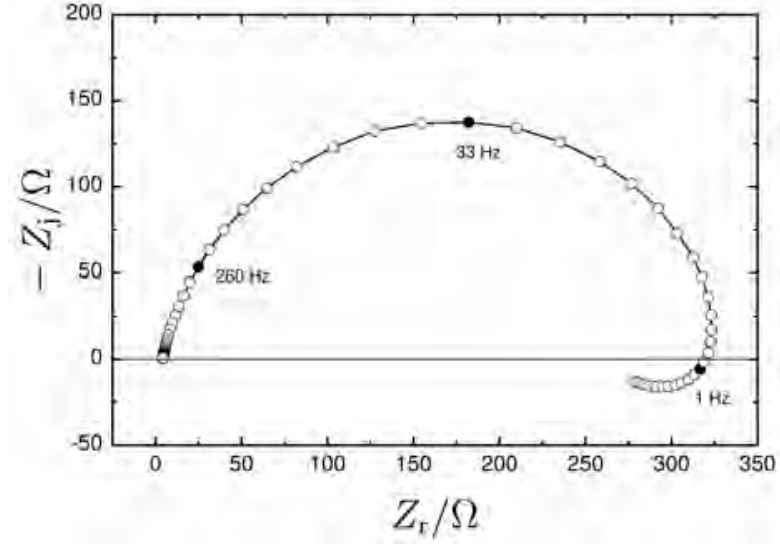

Fig. 6 Electrochemical impedance response for a pure iron electrode in $0.5 \mathrm{M} \mathrm{H}_{2} \mathrm{SO}_{4}$ measured at a potential $E=$ $-0.925 \mathrm{~V}(\mathrm{SSE})$ as indicated in Figure 5(b). Data taken from Wu et al. [4].

on steady-state potential as

$A=\frac{\partial \bar{i}_{\mathrm{F}}}{\partial \bar{\gamma}} \frac{\partial \dot{\gamma}}{\partial \bar{V}}$

where

$\dot{\gamma}=\frac{\partial \gamma}{\partial t}=\frac{i_{(25)}-i_{(26)}}{\Gamma \mathrm{F}}$

When $A=0$, the time-rate-of-change of fractional coverage is independent of steady-state potential, and only a single capacitive loop is seen in the impedance response. When $A>0$, a low-frequency inductive loop is visible, as is shown in Figure 6. The global impedance response given in Figure 6 shows a low-frequency inductive loop which may be associated with the formation of $\mathrm{Fe}(\mathrm{I})$ species adsorbed on the electrode surface.

While the mathematical development is found elsewhere, the results presented here show, from a qualitative perspective, that the low-frequency inductive loop may be attributed to the coupling of electrochemical reactions through an intermediate. In the case of the iron system, the reactions (25) and (26) are coupled through an adsorbed intermediate. A similar coupling of elementary reactions has been proposed for corrosion of magnesium.[9]

Other forms of coupling may also be envisioned. Roy et al.[10] suggested that low-frequency inductive loops, often observed in proton-exchange-membrane (PEM) fuel cells, may be attributed to oxidation of the platinum catalyst. The platinum dissolution was assumed to occur by a reaction scheme similar to that reported by Darling et al.,[11] by an electrochemical reaction

$\mathrm{Pt}+\mathrm{H}_{2} \mathrm{O} \rightleftarrows \mathrm{PtO}+2 \mathrm{H}^{+}+2 \mathrm{e}^{-}$ 
in which $\mathrm{PtO}$ is formed, followed by a chemical dissolution reaction

$\mathrm{PtO}+2 \mathrm{H}^{+} \rightarrow \mathrm{Pt}^{+2}+\mathrm{H}_{2} \mathrm{O}$

The formation of the platinum oxide was proposed to have an indirect influence on the oxygen-reduction reaction at the cathode by changing the effective rate constant for the reaction. Thus,

$K_{\mathrm{eff}}=K_{\mathrm{Pt}}+\left(K_{\mathrm{PtO}}-K_{\mathrm{Pt}}\right) \gamma_{\mathrm{PtO}}$

where $K_{\mathrm{Pt}}$ is the rate constant on a platinum site and $K_{\mathrm{PtO}}$ is the rate constant on a platinum oxide site. The oxygen-reduction reaction was assumed to take place according to

$\mathrm{O}_{2}+4 \mathrm{H}^{+}+4 \mathrm{e}^{-} \rightarrow 2 \mathrm{H}_{2} \mathrm{O}$

with a steady-state current density given by

$\bar{i}_{\mathrm{O}_{2}}=-K_{\mathrm{eff}} \bar{c}_{\mathrm{O}_{2}}(0) \exp \left(-b_{\mathrm{O}_{2}} \eta_{\mathrm{O}_{2}}\right)$

where $K_{\text {eff }}$ is defined by equation (32).

Roy et al.[10] measured the impedance of a PEM fuel cell. The membrane electrode assembly (MEA) was a $0.0308 \mathrm{~mm}$ (2 mil) thick Nafion N112 membrane with a Pt catalyst loading of $0.4 \mathrm{mg} / \mathrm{cm}^{2}$ on both the anode and the cathode sides. The flow channel employed a single-channel horizontal serpentine flow configuration with the outlet lower than the inlet to facilitate removal of condensed water. The active surface area of the MEA was $5 \mathrm{~cm}^{2}$.

A Scribner Associates 850C fuel cell test station was used to control reactant flow rates and temperatures. The test station was connected to a computer by an interface for data acquisition. The $0.1 \mathrm{~L} / \mathrm{min}$ hydrogen gas flow to the anode was held at a temperature of $40 \pm$ $0.1^{\circ} \mathrm{C}$, and the $0.5 \mathrm{~L} / \mathrm{min}$ compressed air gas flow to the cathode was held at a temperature of $35 \pm 0.1^{\circ} \mathrm{C}$. The gas flows were humidified to $100 \%$ relative humidity at the respective temperatures. The cell temperature was held at $40 \pm 0.1^{\circ} \mathrm{C}$.

A typical result is shown in Figure 7. The line represents a model calculation based on the coupling of electrochemical reactions through the oxidation of a platinum catalyst. The diamond is the polarization resistance obtained from the slope of the polarization curve.

The one-dimensional model does not provide an exact fit to the experimental result that was obtained for a system that, given the serpentine gas flow, had a nonuniform current and potential distribution. The model suggests, however, that the coupling of electrochemical reactions through the oxidation of the Pt catalyst can give rise to low-frequency inductive loops.

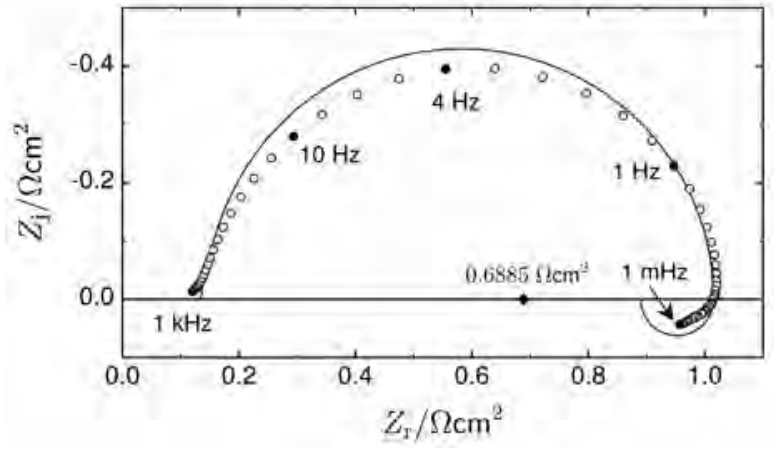

Fig. 7 Electrochemical impedance response for a $5 \mathrm{~cm}^{2}$ nominal surface area PEM fuel cell at a current of $0.2 \mathrm{~A} / \mathrm{cm}^{2}$. The line represents a model calculation based on the coupling of electrochemical reactions through the oxidation of a platinum catalyst. The diamond is the polarization resistance obtained from the slope of the polarization curve. Data taken from Roy et al.[10].

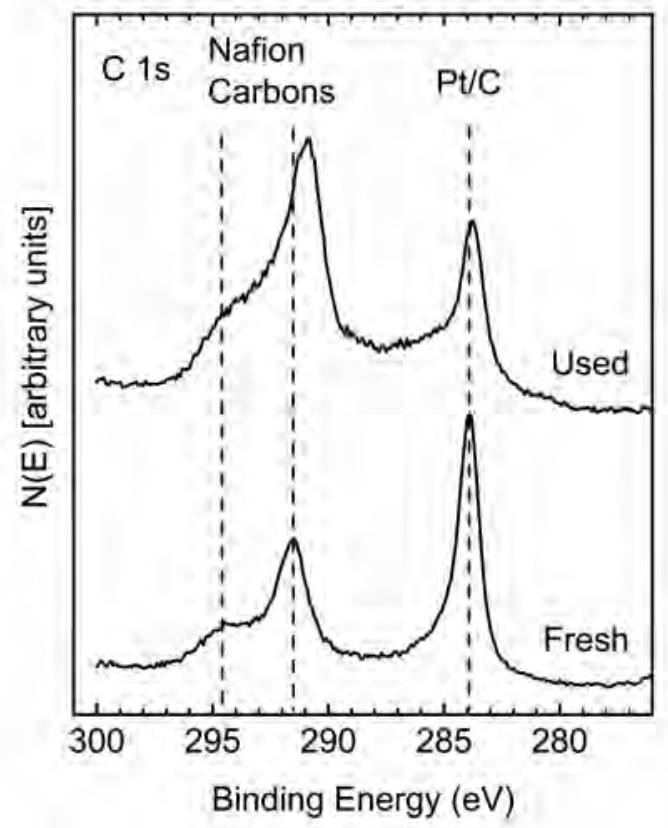

Fig. $8 \mathrm{C}$ 1s high-resolution spectra obtained from un-used and used (after 600 hours of operation) MEA cathode catalyst layers. Taken from Roy et al.[12]

These results can be used to motivate new experimental observations.

Roy et al.[12] report, for example, the results of XRay Photoelectron Spectroscopy obtained from the unused and used MEA cathode catalyst layers. The highresolution spectra from the $\mathrm{C}-1$ s region, shown in Figure 8 , revealed two Nafion ${ }^{\circledR}$-related carbon peaks between binding energies of 291 and $294 \mathrm{eV}$. On the un-used catalyst, the ratio of support carbon to Nafion ${ }^{\circledR}$ carbon was higher than on the used catalyst. This could be due to migration of Nafion ${ }^{\circledR}$ onto the catalyst layer from the 


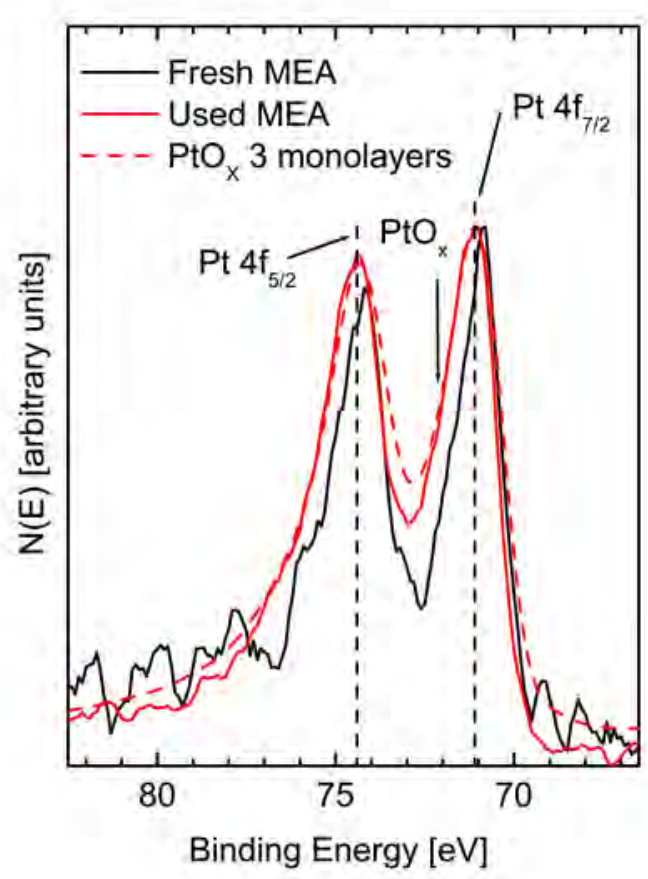

Fig. 9 Pt 4 f high-resolution spectra obtained from un-used and used (after 600 hours of operation) MEA cathode catalyst layers. Taken from Roy et al.[12]

Nafion ${ }^{\circledR}$ membrane due to membrane degradation or to carbon support corrosion.

The high-resolution spectra of the $\mathrm{Pt} 4 \mathrm{f}$ region are presented in Figure 9. The binding energies of the $\mathrm{Pt}$ 4 f peaks $(\sim 71 \mathrm{eV})$ were consistent with those reported for Pt metal [13]. Since the spectra have been normalized, the lower Pt content on the un-used catalyst layer is evident in the lower signal-to-noise ratio of the spectrum obtained from this sample. In addition to a higher $\mathrm{Pt}$ content on the used cathode catalyst layer, the Pt 4f peaks are broader compared to the un-used cathode catalyst layer. There is a significant shoulder at higher binding energies compared to Pt metal. This is indicative of Pt oxidation. Roy et al.[12] observed that the $\mathrm{Pt} 4 \mathrm{f}$ spectrum obtained from 3 monolayers of $\mathrm{PtO}_{\mathrm{x}}$ on $\mathrm{Pt}(100)$, prepared using atomic oxygen, was very similar to the spectrum obtained from the used catalyst layer.[14] They concluded that, after extended operation in the fuel cell, some of the platinum in the catalyst layer was oxidized.

The attribution of the low-frequency inductive loop to $\mathrm{PtO}_{\mathrm{x}}$ formation is sensitive to the reversibility of $\mathrm{PtO}_{\mathrm{x}}$ formation as a function of potential. While the reversibility of $\mathrm{PtO}_{\mathrm{x}}$ formation was not addressed by Roy et al.[12], Mathias et al.[15] reported that the reaction is reversible.
Electrochemical impedance spectroscopy provides a powerful in-situ tool to explore the coupling of electrochemical reactions, yielding insight into reaction mechanisms for electrochemical systems. Indeed, the coupling through adsorbed intermediates can be studied only by measurement of the electrochemical impedance. The interpretation of impedance spectra in terms of a proposed model can be used, as shown in the work presented here for the PEM fuel cell, to guide selection of ex-situ experiments that can be used to either support or reject the proposed mechanism.

\subsection{Identification of Small Rates of Corrosion}

In the special case that both the anodic and the cathodic reactions are controlled by kinetics, the rate of corrosion may be determined from impedance measurements made under the open-circuit condition, or the corrosion potential. The corrosion current may be extracted from the polarization or effective charge-transfer resistance using the Stern-Geary relation[16]

$\bar{i}_{\text {corr }}=\frac{-\beta_{\mathrm{c}} \beta_{\mathrm{a}}}{2.303 \times 10^{3} R_{\mathrm{t}, \mathrm{eff}}\left(\beta_{\mathrm{a}}-\beta_{\mathrm{c}}\right)}$

where $\beta_{\mathrm{a}}$ and $\beta_{\mathrm{c}}$ are the Tafel slopes for anodic and cathodic reactions, respectively, and

$R_{\mathrm{t}, \mathrm{eff}}=\frac{R_{\mathrm{t}, \mathrm{a}} R_{\mathrm{t}, \mathrm{c}}}{R_{\mathrm{t}, \mathrm{a}}+R_{\mathrm{t}, \mathrm{c}}}$

is the effective resistance associated with the parallel contributions of the charge-transfer resistances for the anodic and cathodic reactions. Equation (35) applies for systems such as the corrosion of iron in anaerobic electrolytes, but does not apply for more complicated systems, for example, in aerated electrolytes, where the reactions are not strictly kinetically controlled. In more complex systems, the steady-state corrosion current may be obtained from the charge-transfer resistance of the corrosion reaction, i.e.,

$\bar{i}_{\mathrm{a}}=\frac{\beta_{\mathrm{a}}}{2.303 \times 10^{3} R_{\mathrm{t}, \mathrm{a}}}$

A sophisticated model may be needed to differentiate the corrosion process from the other phenomena and reactions in the system.

An example is provided by Frateur et al.[17], who explored the corrosion of cast iron in Evian ${ }^{\mathrm{TM}}$ drinking water. A film is formed on the cast iron electrodes that includes a porous electrode and porous ferrous films. As the electrolyte is aerated, the cathodic reaction is reduction of oxygen, which is influenced by mass transfer to the pore walls. The anodic reaction is dissolution 
of the cast iron. For this complex system, the corrosion rate was determined from equation (37).

The work of Frateur et al.[17] was motivated by the need to measure the very small internal corrosion rate of cast iron drinking water pipes, used, for example, for the water distribution network in France. While the rate of corrosion is too small to pose structural problems for the pipe network, the small rate of corrosion is sufficient to reduce the concentration of free chlorine $(\mathrm{FCl}$, the sum of hypochlorous acid $\mathrm{HOCl}$ and hypochlorite ions $\mathrm{ClO}^{-}$) introduced in water at the treatment plant in order to maintain microbiological quality. Frateur et al.[17] reported the results of electrochemical impedance measurements that, by use of a model that accounted for anodic metal dissolution, the progressive development of a porous film composed of corrosion product, and oxygen reduction, allowed estimation of corrosion rates. After 28 days of immersion in Evian $^{\mathrm{TM}}$ water, the corrosion rate of the cast iron was observed to be about $10 \mu \mathrm{m} /$ year. This work was supported by surface analyses which showed the presence of corrosion products but could not assess the rate. A corrosion rate this small cannot be assessed by weight-loss measurements. As reported by the authors, "the corrosion of pipes is not a problem itself but it induces a consumption of $\mathrm{FCl}$, which is the real concern of drinking water professionals."

\subsection{Measurement of Film Thickness}

Impedance spectra usually are influenced by distributions of time constants that can often be described in terms of a constant-phase element (CPE). Jorcin et al.[18] and Hirschorn et al.[19] suggested that interpretation of the CPE requires consideration of the nature of the time-constant distribution. A modified power-law distribution of time constants through the thickness of a film was shown by Hirschorn et al.[20,21] to yield a CPE.

The CPE parameters, obtained from

$Z=R_{\mathrm{e}}+\frac{R_{\|}}{1+(\mathrm{j} 2 \pi f)^{\alpha} R_{\|} Q}$

in terms of ohmic resistance $R_{\mathrm{e}}$, a parallel resistance $R_{\|}$, and CPE parameters $\alpha$ and $Q$, were expressed in terms of film thickness $\delta$, dielectric constant $\varepsilon$, and the resistivity at the film-electrolyte interface as $\rho_{\delta}$ as

$Q=\frac{\left(\varepsilon \varepsilon_{0}\right)^{\alpha}}{g \delta \rho_{\delta}^{1-\alpha}}$

where $\varepsilon_{0}$ is the permittivity of vacuum, and

$g=1+2.88(1-\alpha)^{2.375}$

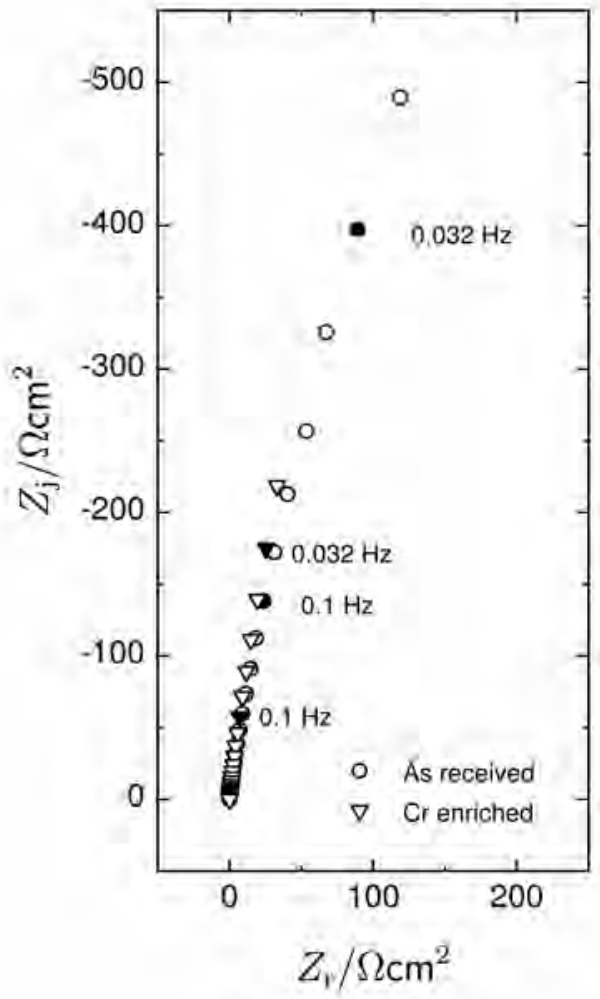

Fig. 10 Impedance data for free-machining 18/8 stainless steel in an electrolyte consisting of $22 \mathrm{~g} / \mathrm{L}$ boric acid with $\mathrm{NaOH}$ added, about $6 \mathrm{~g} / \mathrm{L}$, to bring the $\mathrm{pH}$ to 7.2 (at the edge of buffering region). Data are presented for the steel in as-received condition and after a proprietary treatment to increase the chromium content of the oxide film. Data taken from Orazem et al.[23]

with a value close to unity.

Equation (39) may be a considered a single equation with known values for $Q$ and $\alpha$ and unknown values for $\varepsilon, \delta$, and $\rho_{\delta}$. In practice, however, $\varepsilon$ is generally known for a given oxide film, and $\rho_{\delta}$ may be obtained by calibration. [22] The application of equation (39) was explored by Orazem et al.[23], who reported impedance responses for free-machining 18/8 stainless steel (18 Cr$8 \mathrm{Ni}$ ), also known as 303 stainless steel, in an electrolyte consisting of $22 \mathrm{~g} / \mathrm{L}$ boric acid with $\mathrm{NaOH}$ added, about $6 \mathrm{~g} / \mathrm{L}$, to bring the $\mathrm{pH}$ to 7.2 The results are presented in Table 1. As shown in Table 2, application of equation (39) yielded film thicknesses in close agreement to values obtained from ex-situ XPS. The power-lawmodel analysis is now used commercially for screening raw materials. Riemer and Orazem[24] reported that "The impedance based screening of raw materials has a tremendous positive impact in an industry where the state of the oxide film on stainless steel strongly influences process and product performance. Having a fast, inexpensive and accurate measure of the film thickness is of great benefit in the manufacturing process. With 
Table 1 Regression results for free-machining 18/8 stainless steel in an electrolyte consisting of $22 \mathrm{~g} / \mathrm{L}$ boric acid with $\mathrm{NaOH}$ added to bring the $\mathrm{pH}$ to 7.2. Data taken from Orazem et al.[23]

\begin{tabular}{c|c|c}
\hline & As Received & After Treatment \\
\hline$R_{\mathrm{e}}, \Omega \mathrm{cm}^{2}$ & 15.3 & 13.3 \\
$R_{\|}, \mathrm{M} \Omega \mathrm{cm}^{2}$ & 2.33 & 16.8 \\
$\alpha$ & 0.91 & 0.91 \\
$Q, \mu \mathrm{F} / \mathrm{s}^{(1-\alpha)} \mathrm{cm}^{2}$ & 11 & 30.5 \\
\hline$\delta$ by XPS, $\mathrm{nm}$ & 6.3 & 2.5 \\
\hline
\end{tabular}

Table 2 Film thickness obtained by application of equation (39) to impedance results for free-machining 18/8 stainless steel in an electrolyte consisting of $22 \mathrm{~g} / \mathrm{L}$ boric acid with $\mathrm{NaOH}$ added to bring the $\mathrm{pH}$ to 7.2 .

\begin{tabular}{c|ccc} 
Method & Sample 1 & Sample 2 & Sample 3 \\
\hline XPS & $2.0 \mathrm{~nm}$ & $6.3 \mathrm{~nm}$ & $2.5 \mathrm{~nm}$ \\
EIS & $1.7 \mathrm{~nm}$ & $5.9 \mathrm{~nm}$ & $2.7 \mathrm{~nm}$
\end{tabular}

such a technique, process excursions such as a small air leak in an annealing furnace can be diagnosed and remedied within hours, thereby preventing large amounts of product loss and possible shipping delays."

\section{Conclusions}

Electrochemical impedance spectroscopy is a transferfunction method applied to electrochemical processes. The technique has an exciting capability to quantify important properties, but, as shown in the present work, detailed interpretation requires system-specific models.

The present tutorial provides a qualitative appreciation for impedance spectroscopy and its unique power to extract important properties for electrochemical systems. Excellent textbooks on the subject are available, such as Lasia [25] and Orazem and Tribollet [1]. Research monographs, e.g., Lvovich [26] Barsoukov and Macdonald [27], are also available, but these are better suited for those more advanced in the art.

Acknowledgements The authors thank Prof. Mamie Sancy (Pontificia Universidad Católica) and Prof. Maritza Paez (Universidad de Santiago de Chile) for the opportunity to present the present work at the "First Workshop of Material Science for Corrosion Protection" held in 2017 in Santiago, Chile. The authors thank Prof. Dr. Fritz Scholz (Universität Greifswald) for the invitation to submit this tutorial. Mark Orazem acknowledges financial support from the University of Florida Foundation Preeminence and the Dr. and Mrs. Frederick C. Edie term professorships.

\section{Conflict of interest}

The authors declare that they have no conflict of interest.

\section{References}

1. M.E. Orazem, B. Tribollet, Electrochemical Impedance Spectroscopy, 2nd edn. (John Wiley \& Sons, Hoboken, 2017)

2. J.S. Newman, Journal of the Electrochemical Society 113(5), 501 (1966)

3. M.E. Orazem, N. Pébère, B. Tribollet, Journal of the Electrochemical Society 153, B129 (2006)

4. S.L. Wu, M.E. Orazem, B. Tribollet, V. Vivier, Journal of the Electrochemical Society 156(7), C214 (2009)

5. J.O.M. Bockris, D. Drazic, A.R. Despic, Electrochimica Acta 4, 325 (1961)

6. I. Epelboin, M. Keddam, Journal of the Electrochemical Society 117, 1052 (1970)

7. R.D. Armstrong, R.E. Firman, H.R. Thirsk, Faraday Discussions 56, 244 (1973)

8. I. Epelboin, M. Keddam, J.C. Lestrade, Faraday Discussions 56, 264 (1973)

9. G. Baril, G. Galicia, C. Deslouis, N. Pèbére, B. Tribollet, V. Vivier, Journal of the Electrochemical Society 154, C108 (2007)

10. S.K. Roy, M.E. Orazem, B. Tribollet, Journal of the Electrochemical Society 154, B1378 (2007)

11. R.M. Darling, J.P. Meyers, Journal of the Electrochemical Society 150, A1523 (2003)

12. S.K. Roy, H. Hagelin-Weaver, M.E. Orazem, Journal of Power Sources 196(8), 3736 (2011)

13. J. Moulder, W. Stickel, P. Sobol, K. Bomben, Handbook of X-Ray Photoelectron Spectroscopy (PhysicalElectronics, Inc., Eden Prairie, 1995)

14. R.B. Shumbera, H.H. Kan, J.F. Weaver, Surface Science 601, 235 (2007)

15. Y. Liu, M. Mathias, J. Zhang, Electrochemical and SolidState Letters 13, B1 (2010)

16. M. Stern, A.L. Geary, Journal of the Electrochemical Society 104, 56 (1957)

17. I. Frateur, C. Deslouis, M.E. Orazem, B. Tribollet, Electrochimica Acta 44, 4345 (1999)

18. J.B. Jorcin, M.E. Orazem, N. Pébère, B. Tribollet, Electrochimica Acta 51, 1473 (2006)

19. B. Hirschorn, M.E. Orazem, B. Tribollet, V. Vivier, I. Frateur, M. Musiani, Electrochimica Acta 55, 6218 (2010)

20. B. Hirschorn, M.E. Orazem, B. Tribollet, V. Vivier, I. Frateur, M. Musiani, Journal of the Electrochemical Society 157, C452 (2010)

21. B. Hirschorn, M.E. Orazem, B. Tribollet, V. Vivier, I. Frateur, M. Musiani, Journal of the Electrochemical Society 157, C458 (2010)

22. M.E. Orazem, B. Tribollet, V. Vivier, D.P. Riemer, E.A. White, A.L. Bunge, Journal of the Brazilian Chemical Society 25, 532 (2014)

23. M.E. Orazem, B. Tribollet, V. Vivier, S. Marcelin, N. Pébère, A.L. Bunge, E.A. White, D.P. Riemer, I. Frateur, M. Musiani, Journal of the Electrochemical Society 160, C215 (2013)

24. D.P. Riemer, M.E. Orazem, ECS Interface 23(3), 63 (2014)

25. A. Lasia, Electrochemical Impedance Spectroscopy and Its Applications (Springer, New York, 2014)

26. V.F. Lvovich, Impedance Spectroscopy: Applications to Electrochemical and Dielectric Phenomena (Wiley, Hoboken, 2015)

27. E. Barsoukov, J.R. Macdonald (eds.), Impedance Spectroscopy: Theory, Experiment, and Applications, 3rd edn. (John Wiley \& Sons, Hoboken, 2018) 